but only as a working hypothesis without any claim to infallibility or permanency; if substantial evidence can be brought against it, then we hope to have the pleasure of building up another. But if the aqueous humour possesses all the very definite and complicated chemical and physical properties of a dialysate, both in its normal condition and in variations from the normal, if it can be shown, not to be in "supposed osmotic equilibrium," but to fulfil, in experimental fact, the complex and peculiarly exacting hydrostatic, osmotic, electrical, and chemical conditions required by a system in thermo-dynamical equilibrium with capillary plasma, and if at the same time no adequate objection is put forward or alternative and unassailable explanation is advanced, there seems to be no valid reason at the present time against the adoption of such a working hypothesis.

\title{
ANNOTATIONS
}

\section{The International Congress of Ophthalmology, 1929}

We have much pleasure in announcing that the re-establishment of International Congresses of Ophthalmology is an accomplished fact. The next Congress will take place in Holland in September, 1929. This satisfactory conclusion to negotiations which have spread over several years is due in the first place to the perseverance and tact of the Anglo-American Committee which was appointed by the English-Speaking Conference of Ophthalmology. Of the members of that Committee the chief burden has fallen upon $\mathrm{Mr}$. Treacher Collins, the chairman, and Mr. Leslie Paton, the secretary. Even their efforts, however, might have been frustrated had it not been for the genius and geniality of Dr. van der Hoeve, of Leyden, who presided over the Conference of delegates from all nations which met in July at Scheveningen. The congratulations and thanks of all ophthalmologists throughout the world are due, and will be willingly and gratefully accorded, to these three intermediaries in the re-establishment of plenary international relations so far as they affect ophthalmology.

\section{William Mackenzie Memorial}

On another page of this number will be found an announcement of a proposed memorial to the great Scottish ophthalmologist of the last century. Details will be found in the note; and it is only 
necessary here to express the hope that the fund will meet with a liberal support. . In England there are several honours of this kind, e.g., the Middlemore Lecture, the Nettleship Medal, and the Gifford-Edmunds Prize; it is only fitting that the genius of the great Mackenzie should receive this recognition at the seat of his labours.

To those who know anything about the rise of ophthalmology in this country it is unnecessary to say anything about Mackenzie, and those who do not know much about him should read the memoir by Dr. Freeland Fergus in Vol. I ; and having read that they might do well to read his epoch-making textbook. No surer way of keeping his memory green can be conceived than this proposed medal for the encouragement of ophthalmological research. The elders of the ophthalmic fraternity can echo the words of the writer of Ecclesiasticus: "Let us now praise famous men and the fathers that begat us"; while the younger among us should strive to follow in his footsteps.

\section{Ophthalmic Folk Lore}

"The Diary of a Country Parson," Vol. III, by the Reverend James Woodforde has just been published by Humphrey Milford, and contains help for every ophthalmic surgeon. The present volume continues the daily account of his life at Weston Longeville in Norfolk during the years 1788 to 1792 .

On March 10, 1791, he notes: "My right Eye-lid very much swelled and inflamed having a Stiony on it, very painful all day." On March 11 he says : "The Stiony on my right Eye-lid still swelled and inflamed very much. As it is commonly said that the Eye-lid being rubbed by the tail of a black Cat would do it much good if not entirely cure it, and having a black Cat, a little before dinner I made a trial of it, and very soon after dinner I found my Eye-lid much abated of the swelling and almost free from Pain. I cannot therefore but conclude it to be of the greatest service to a Stiony on the Eye-lid. Any other Cats Tails may have the above effect in all probability-but I did my Eye-lid with my own black Tom Cat's Tail."

It is, therefore, clear that no ophthalmic surgeon's equipment is complete if he has only a slit-lamp, he must also invest in a black Tom Cat. The author does not note if the Tail of a black Tom Cat can be used more than once, but owing to the number of such animals seen prowling round Harley Street, Wimpole Street, and Welbeck Street, it seems probable that after having been once used for this important therapeutic purpose, they are cruelly dismissed by their breeders, the physician-ophthalmologists, who are aware of this remedy for Stiony. 